\title{
Pedagogia Feminista como processo educativo para a reflexão da política pública de ATER no Nordeste
}

\author{
MORAES, Lorena Lima de 1 \\ JALIL, Laeticia Medeiros ${ }^{2}$ \\ SANTOS, Janaína Henrique dos ${ }^{3}$ \\ COSTA, Michelly Aragão Guimarães ${ }^{4}$ \\ OLIVEIRA, Maria do Socorro de Lima ${ }^{5}$
}

\section{Resumo}

O presente artigo versa sobre processos educativos não-formais e feministas direcionados para a reflexão da Política Nacional de ATER voltada para mulheres rurais que constroem a agroecologia. Neste sentido, iremos nos deter à experiência do "Projeto ATER, Feminismo e Agroecologia", realizado durante três anos (2014-2017), no qual foram construídas e executadas metodologias e estratégias que buscam romper com a lógica da transmissão do conhecimento - numa via de mão única e hierarquizada - potencializando a troca de saberes, a valorização de vozes e histórias para a construção horizontal e dialógica do conhecimento e, sobretudo, para pensar a política pública vivida pelas mulheres a partir das suas realidades. Afirmamos a importância de se construir uma pedagogia feminista para desorganizar as relações de poder de forma subversiva e revolucionária, considerando o valor da subjetividade na criação histórica e o valor dos corpos inscritos nos territórios. Concluímos que o aprender-fazendo em rede a partir da análise da política como instrumento, mas para além disso, como potencialidade da política vivida nos territórios, nos permitiu elucidar canais de

1 Cientista social com Doutorado em Ciências Sociais (UERJ), docente na Universidade Federal Rural de Pernambuco - Unidade Acadêmica de Serra Talhada (UFRPE/UAST) e líder do Dadá: Grupo de Pesquisa em Relações de Gênero, Sexualidade e Saúde. Foi membro do Projeto ATER, Feminismo e Agroecologia e faz parte da Rede Feminismo e Agroecologia do Nordeste. Ilorenamoraes@gmail.com

2 Cientista social com Doutorado em Ciências Sociais (UFFRJ), docente na Universidade Federal Rural de Pernambuco (UFRPE) - Campus Dois Irmãos e líder do Núcleo Jurema: Feminismos, Agroecologia e Ruralidades. Foi coordenadora do Projeto ATER, Feminismo e Agroecologia e faz parte da Rede Feminismo e Agroecologia do Nordeste. laeticiajalil@gmail.com

3 Cientista social com Mestrado em Antropologia (UFRN), Assessora técnica na Associação de Apoio às Comunidades do Campo do Rio Grande do Norte (AACC-RN). Foi membro do Projeto ATER, Feminismo e Agroecologia e faz parte da Rede Feminismo e Agroecologia do Nordeste. naina_henrique@yahoo.com.br

4 Administradora, mestra em Administração rural e doutoranda em Ciências Sociais pela Universidade de Buenos Aires. Pesquisadora do Programa Poscolialidade, pensamiento fronterizo y transfronterizo en los estudios feministas (IDAES/UNSAM); integrante do Dadá: Grupo de Pesquisa em Relações de Gênero, Sexualidade e Saúde. Foi membro do Projeto ATER, Feminismo e Agroecologia e faz parte da Rede Feminismo e Agroecologia do Nordeste. mikellyaragao@gmail.com

5 Cientista social com Doutorado em Ciências Sociais (UFCG), docente na Universidade Federal Rural de Pernambuco (UFRPE) - Campus Dois Irmãos, integrante do Núcleo Jurema: Feminismos, Agroecologia e Ruralidades e do Dadá: Grupo de Pesquisa em Relações de Gênero, Sexualidade e Saúde. Foi coordenadora do Projeto ATER, Feminismo e Agroecologia e faz parte da Rede Feminismo e Agroecologia do Nordeste. socorrololiveira@gmail.com 
confluência, princípios e metodologias que visibilizassem conhecimentos, saberes e transformações na vida das mulheres rurais.

\title{
Mulheres Rurais. Pedagogias Feministas. ATER. Agroecologia. Construção do Conhecimento. \\ Feminist Pedagogy as an educational process for the reflection of the ATER public policy in the northeast region of Brazil
}

\begin{abstract}
This article presents about non - formal and feminist educational processes directed towards the reflection of the National Policy of ATER directed at rural women who construct agroecology. In this sense, we will look at the experience of the "ATER Project, Feminism and Agroecology", carried out over three years (2014-2017), in which methodologies and strategies that seek to break with the logic of knowledge transmission were constructed and executed - in a way of a single and hierarchical hand potentializing the exchange of knowledge, the valorization of voices and stories for the horizontal and dialogical construction of knowledge and, above all, for thinking about the public policy lived by women from their realities. We affirm the importance of constructing a feminist pedagogy to disorganize the relations of power in a subversive and revolutionary way, considering the value of subjectivity in historical creation and the value of the bodies inscribed in the territories. We conclude that learning-networking as a tool, but also as a potential of the politics lived in the territories, allowed us to elucidate channels of convergence, principles and methodologies that make knowledge, knowledge and women.
\end{abstract}

\section{Rural Women. Feminist Pedagogies. ATER. Agroecology. Knowledge Building.}

\section{Introdução}

O presente artigo versa sobre processos educativos não-formais e feministas direcionados para a reflexão de uma política pública voltada para mulheres rurais que constroem agroecologia ${ }^{6}$. Neste sentido, iremos nos deter à experiência de um projeto realizado durante três anos (2014-2017), no qual foram construídas e executadas metodologias e estratégias que rompem com a lógica da transmissão de conhecimento - numa via de mão única e hierarquizada - potencializando a troca de saberes, a valorização de vozes e histórias para a construção horizontal do conhecimento e, sobretudo, para pensar a política pública vivida pelas mulheres rurais a partir das suas realidades.

Assim, este trabalho será desenvolvido com base na epistemologia feminista que considera que todo conhecedor/a, assim como o conhecimento produzido por essas/es, é localizado, negando a apregoada noção de objetividade, conforme reflexões de Haraway (1995). Reafirmamos o nosso lugar

6 "A Agroecologia é entendida como enfoque científico, teórico, prático e metodológico, com base em diversas áreas do conhecimento, que se propõe a estudar processos de desenvolvimento sob uma perspectiva ecológica e sociocultural e, a partir de um enfoque sistêmico - adotando o agroecossistema como unidade de análise - apoiar a transição dos modelos convencionais de agricultura e de desenvolvimento rural para estilos de agricultura e de desenvolvimento rural sustentável". Fonte: Associação Brasileira de Agroecologia (ABA). 
de fala, como parte do processo que nos propomos a apresentar de forma reflexiva e crítica.

Retomar os passos dados e as escolhas do grupo é de certa forma, um exercício rico e complexo para pensar a nossa realidade, a partir das distintas histórias e vivências, e percebermos que a construção do conhecimento desde a pedagogia feminista nos tira de "certos lugares de conforto", mas sobretudo, nos recoloca no mundo como sujeitos políticos coletivos. Não existe um feminismo, isso é certo. Mas o/s feminismo/s se reafirma $/ \mathrm{m}$ para nós, como instrumentos de luta, uma crítica e potente lente de análise da realidade e um movimento social que nos fortalece para as transformações políticas, sociais e culturais emergentes e urgentes.

Neste contexto, o projeto denominado "ATER7, Feminismo e Agroecologia" se estabeleceu através da parceria entre a Universidade Federal Rural de Pernambuco - UFRPE, Universidade Federal do Ceará - UFC e a Diretoria de Políticas para as Mulheres Rurais e Quilombolas - DPMRQ, do extinto Ministério do Desenvolvimento Agrário - MDA. O projeto teve como objetivo desenvolver processos formativos em rede junto às organizações, movimentos sociais mistos (que integram mulheres e homens) e feministas, que atuam no campo agroecológico em chamadas públicas específicas de Assistência Técnica e Extensão Rural: ATER Mulher e ATER Agroecologia8. Para tal, assumimos o desafio de "fazer diferente", pois tínhamos "perguntas diferentes" e novos objetivos para a análise da política pública junto às mulheres rurais que provocavam questões para além do modelo de desenvolvimento econômico, mas sobretudo, alguns questionamentos que "abalavam" a cultura patriarcal e machista da nossa sociedade, expressadas na política de ATER.

Esse fazer diferente, chamamos de projeto/processo, onde realizamos seminários, intercâmbios, sistematizações de experiências, cartografia social e feminista, e outras formas de linguagem - subjetivas e corporais - foram incorporadas na busca de construir coletivamente metodologias para pensar uma ATER feminista, agroecológica, despatriarcal, antirracista, anticapitalista, descolonizadora, emancipadora e que contribua para a autonomia das mulheres.

O projeto contou com aproximadamente setenta (70) mulheres da região nordeste do Brasil (com representações dos nove estados), dentre elas agricultoras, indígenas, quilombolas, alunas, professoras, assessoras técnicas de ATER, pesquisadoras, mulheres rurais e urbanas, jovens, contemplando uma ampla diversidade étnico-racial e geracional.

Essa "nova forma de fazer" e perceber a política vivida exigiu da equipe outros saberes e abertura para o novo, para o desconhecido no campo

\footnotetext{
7 Assistência Técnica e Extensão Rural.

8 Destaca-se que há uma exigência para a execução de projetos de ATER no marco das chamadas públicas é a delimitação do público beneficiário de todas as chamadas vinculadas a Lei de ATER, em que devem ter no mínimo 50\% de mulheres como beneficiárias; $30 \%$ dos recursos destinados a atividades específicas com mulheres, equipe técnica formada por mulheres e espaço específico para crianças.
} 
metodológico. Além de incorporar questões como a divisão sexual do trabalho, renda, democracia, relações de trabalho, enfrentamento à violência, racismo, conflitos agrários, espiritualidade, cuidados, bem viver e querer, o nosso desafio foi refletir todas essas temáticas à luz das nossas diferenças, e pensar/questionar a mesma política pública a partir das lentes do feminismo em convergência com a agroecologia.

Assim, este texto está dividido em três partes: a primeira aborda a contextualização da política pública de ATER sob a perspectiva de gênero; a segunda destaca o feminismo como teoria, prática e movimento para a construção de uma pedagogia feminista e popular, constituindo o embasamento para a nossa reflexão; e, na terceira descrevemos as metodologias vivenciadas por todas as integrantes do projeto, para a construção de uma reflexão feminista, libertadora e dialógica sobre uma política pública.

\section{Assistência Técnica e Extensão Rural no Brasil: contextualizando sob a perspectiva de gênero}

A Assistência Técnica e Extensão Rural (ATER) se institucionalizou no Brasil, no contexto da política desenvolvimentista do período pós-guerra alinhada ao projeto de modernização da agricultura, com o objetivo de promover a transferência de conhecimentos e dos pacotes tecnológicos agropecuário para os produtores rurais (FONSECA, 1985). O caráter técnico da política se materializava através da transmissão unilateral de conhecimentos referentes à produção agrícola, com a finalidade de corresponder os interesses das grandes empresas transnacionais do ramo, conhecido também como difusionismo tecnológico.

De acordo com Calaça (2018) o Brasil desenvolvimentista investiu fortemente em uma política agrícola subordinada à indústria e fomentou a implantação de grandes campos de monocultura para a produção em larga escala e ampliação das fronteiras agrícolas, desencadeando consequências nefastas para as questões fundiárias, agrárias, sociais e ambientais. A política de ATER no Brasil entre 1940 e 1970 se desenvolveu de maneira conservadora e androcêntrica desconsiderando o trabalho das mulheres nos quintais produtivos, na roça e na casa, reproduzindo uma lógica patriarcal que restringia a ampla cidadania e autonomia das mulheres.

Neste modelo também se afirma a figura da família e do chefe de família como beneficiário das políticas públicas voltadas para o meio rural brasileiro, como se a unidade familiar fosse desprovida de relações de poder, de opressão e violência. Essa lógica essencialista da família rural permeou as percepções de gestores públicos até muito pouco tempo. Rodica Weitzman (2011, p. 89) chama atenção para a falácia que se esconde atrás da "lógica essencialista em torno da unidade familiar, como se fosse destituída de conflitos internos e desigualdades sociais". É esta perspectiva "abrangente e inclusiva" que exclui e invisibiliza as 
mulheres, que pouco usufruíam da política e raramente conquistavam um papel ativo na mesma (BUTTO; HORA, 2008). Para Weitzman (2011):

O enquadramento das mulheres em um lugar estático, de extrema passividade enquanto meras "beneficiárias indiretas" de ações voltadas para os homens - vistos como os "chefes da família" e "porta-vozes" das atividades agrícolas - é um legado que se explica, em grande parte, pela própria concepção ideológica que embasa sua criação (p. 89).

Somente a partir de 1980, com o processo de redemocratização do Brasil e a revitalização dos movimentos sociais, a política de ATER sofre modificações no contexto da prestação de serviços, incorporando metodologias que contemplavam os processos de formação e organização comunitária.

Contudo, ainda assim, permaneceu a dificuldade de reconhecer e visibilizar a diversidade de trabalhos desenvolvidos pelos diferentes sujeitos do grupo familiar para além dos papéis de gênero e superar o caráter tecnicista e familista enraizado desde a construção da política. Atividades que estimulavam a produção de doces, geleias, pães, pinturas em panos de prato eram comuns nos programas de formação voltados para as mulheres, sendo poucos os projetos que incentivavam a participação das mulheres em espaços públicos e políticos, em atividades técnicas agrárias e de gestão de empreendimentos. Já, as intervenções voltadas para os homens estavam voltadas aos conhecimentos e tecnologias agrícolas para a produção, pautando-se na ideia do benefício ao núcleo familiar, ou seja, se os homens estão participando, os interesses das mulheres e dos/as filhos/as consequentemente estariam garantidos. A perspectiva deste modelo de ATER reafirmava a injusta divisão sexual do trabalho e os papéis tradicionais no meio rural, reforçados pela maioria das organizações que prestavam assistência técnica.

Em 2003, a Política Nacional de ATER (PNATER) se reestrutura a partir de novos arranjos institucionais elencando uma visão de desenvolvimento rural mais ampla e democrática, ao olhar para sujeitos até então historicamente excluídos. Desde a criação da política, pela primeira vez se buscou incluir enfoques de gênero, geração, raça e etnia - numa perspectiva de abordar estas questões de forma integradora, para o centro das orientações dos projetos e programas de ATER. É válido destacar que a reestruturação da política está inserida num contexto de abertura para o diálogo entre diversas esferas do Governo Federal, movimentos sociais e organizações não governamentais (ONGs) que prestavam assessoria técnica às mulheres rurais (especial destaque as instituições que atuavam no campo agroecológico e feminista).

A PNATER foi implementada através do Programa Nacional de Assistência Técnica e Extensão Rural na Agricultura Familiar e na Reforma 
Agrária (PRONATER), que tinham como instrumento orientador estabelecer as diretrizes e metas para os serviços públicos de ATER no Brasil. É importante demarcar três mudanças paradigmáticas que previam modificar a estruturação interna da política e a operacionalização do PRONATER, a exemplo dos critérios básicos para o credenciamento de entidades prestadoras de serviços: i) adoção da agroecologia como matriz tecnológica e o reconhecimento da pluriatividade e diversidade de populações que compõe o movimento da agricultura familiar; ii) a necessidade de incluir metodologias participativas integradas às dinâmicas locais e possibilitar a participação popular na construção do conhecimento; iii) apoiar ações específicas voltadas à construção da equidade social e valorização da cidadania, visando à superação da discriminação, da opressão e da exclusão das mulheres trabalhadoras rurais, jovens rurais, quilombolas e indígenas (WEITZMAN, 2011).

Rodica Weitzman (2011) destaca que, embora as diretrizes do Programa incluam as dimensões de gênero, raça e etnia, não previa ações efetivas que reconheçam as especificidades das mulheres a partir de suas diferenças socioeconômicas, proporcionando autonomia econômica, inclusão das mulheres na gestão ou no fortalecimento de redes de produção. Portanto, em 2008, foi implementado o Programa de Organização Produtiva de Mulheres Rurais, com a finalidade de promover a autonomia econômica para as mulheres, facilitar o acesso a outras políticas e programas do Governo Federal, divulgar a produção das mulheres em feiras nacionais e fortalecer os empreendimentos da economia solidária.

A PNATER foi se aperfeiçoando, desde a sua concepção, sofrendo alterações inclusive na sua perspectiva conceitual e ideológica. A reestruturação da PNATER foi um marco nesta trajetória, porém, percebeu-se a necessidade de ampliar o foco acerca do discurso de "inclusão social", que na prática não se fazia consistente, deixando as mulheres na mesma condição de "beneficiária indireta" ou usufruindo de ações que reproduziam a injusta divisão sexual do trabalho.

Na prática, os projetos de ATER, mesmo diante das alterações no texto da política, ainda pecavam pela ausência de uma abordagem metodológica que incorporasse a discussão de gênero de forma coerente e efetiva em suas ações. Desta forma, se fazia necessário construir espaços de reflexão sobre a atuação dos/as assessores/as técnicos/as na execução da política de ATER, com a proposta de discutir as ações técnicas para todos/as membros da propriedade, bem como, provocar e incorporar a discussão sobre os temas do âmbito social a partir da perspectiva de gênero e da agroecologia, para reconstruir o modelo de desenvolvimento rural integral.

Desta forma, constituiu-se o projeto "ATER, Feminismo e Agroecologia", um convite do Governo Federal que nos possibilitou criar este espaço, construído 
e inspirado na pedagogia feminista e da educação popular, para problematizar e complexificar as execuções dos projetos de ATER na Região Nordeste.

\subsection{O projeto ATER, Feminismo e Agroecologia: um desafio, um processo}

Em meados de 2013, recebemos um convite da extinta Diretoria de Políticas Públicas para as Mulheres Rurais e Quilombolas (DPMRQ), do então Ministério do Desenvolvimento Agrário (MDA), através da professora Karla Hora $^{9}$, para construir um projeto de formação em ATER na perspectiva do feminismo e da agroecologia. O projeto se estabeleceu numa parceria entre Universidade Federal Rural de Pernambuco (UFRPE) ${ }^{10}$, a Universidade Federal do Ceará (UFC) ${ }^{11}$ e a DPMRQ/MDA.

Naquele momento não tínhamos nada delineado. Havia uma demanda urgente por formação que vinha das experiências das chamadas públicas de ATER implementadas nos territórios em que as questões referentes aos temas "específicos" (mulheres e agroecologia) ficavam muito aquém do desejado. Construímos um processo a partir da confiança política e ideológica entre diferentes sujeitos: universidade - professoras e estudantes; representantes do governo; militantes dos movimentos sociais feministas e mistos e técnicas de organizações de ATER, acreditando que "Sem Feminismo não há Agroecologia”.

Por isso, o denominamos de projeto/processo, uma vez que a proposta foi se constituindo durante o processo de execução, entre 2014 e 2017 . Não se tinha um esboço desenhado, mas existia um horizonte, que apontava para identificar, pesquisar, reconhecer, visibilizar e fortalecer as experiências de Assistência Técnica e Extensão Rural (ATER) na região nordeste, proporcionadas pelos editais públicos de ATER Mulher e ATER Agroecologia. Como também, reconhecer a necessidade de fortalecer os processos, as trajetórias e os acúmulos das organizações que já atuavam com ATER no campo da agroecologia e do feminismo nesta região.

O convite chegou como uma oportunidade de fortalecer a política pública de ATER, bem como, as mulheres rurais e as organizações diretamente envolvidas e as assessoras técnicas participantes. Destaca-se que, naquele momento não estávamos sob um golpe misógino, machista e classista contra nossa democracia, e percebemos que este projeto poderia ser um instrumento para nos fortalecer (como um coletivo feminista na Região Nordeste) e assim aceitamos o desafio.

9 Engenheira, Profa ${ }^{a}$. Dra ${ }^{\text {a }}$ Da UFG. Ex Diretora da Diretoria de Políticas Públicas para as Mulheres Rurais e Quilombolas (DPMRQ).

10 As professoras Laeticia Jalil e Maria do Socorro Lima Oliveira coordenaram o projeto pela UFRPE. 11 A professora Gema Galgani Esmeraldo coordenou o projeto pela UFC. 
Diante do processo de construção do projeto e da possibilidade de criar a partir de uma leitura crítica sobre a realidade nos territórios em que as experiências de fato eram desenvolvidas, foram definidas a realização de diversas atividades como formação política e pedagógica nos territórios que executavam as chamadas de ATER; Formação para as participantes diretas totalizando 6 seminários regionais; A construção de uma cartografia feminista; Intercâmbios entre agricultoras e feiras da economia solidária; sistematização das experiências de ATER e Feminismo na região nordeste; Pesquisa sobre os impactos da política de ATER na vida das mulheres rurais; Produção de material audiovisual e de uma campanha educativa.

O projeto, "ATER, Feminismo e Agroecologia”, foi nomeado coletivamente durante o processo e se constituiu como um instrumento político para todas nós, a partir da apropriação coletiva e da adoção de uma pedagogia crítica feminista.

2 Pedagogia feminista: um processo educativo pensado pelas mulheres para a construção de um mundo mais democrático para todos/as

O feminismo é um movimento social de mulheres que possui um caráter civilizatório ao reivindicar liberdade e autonomia para todas as mulheres, mas também, para todas as pessoas. O feminismo questiona os princípios estruturantes da sociedade que explora, domina e violenta a humanidade e chama todas as pessoas a intervirem na realidade social (HOOKS, 2017). Neste sentido, entendemos o feminismo como um pensamento crítico que embasa a ação política a fim de transformar a realidade através de práticas antirracistas, antissexistas, anticlassistas e anti-homofóbicas.

A resistência cotidiana das mulheres às formas de dominação e exploração alimenta o movimento em diferentes dimensões. Carmen Silva (2010, p. 26) afirma que "o feminismo é um apoio à dimensão individual da emancipação, à auto constituição como sujeito da própria vida, e, ao mesmo tempo, um instrumento para o enfrentamento coletivo da dominação e exploração das mulheres".

bell hooks chama atenção para o poder transformador do feminismo ao percebê-lo como um processo educativo de tomada de consciência das desigualdades de gênero, raça e classe e alerta sobre a importância de reportarmos à teoria dentro do ativismo, sobretudo, para não perdermos de vista as diversas formas de dominação existentes.

Para nós, o feminismo é um modo de olhar o mundo (uma nova lente) e também uma perspectiva de vida; é um movimento político e uma construção teórica que visa à transformação da situação das mulheres e o questionamento às relações de poder (teoria descritiva, analítica e sobretudo prescritiva, pois visa a intervenção na realidade e sua transformação). Além de fomentar a prática da 
militância organizada, nas últimas décadas, tem se tornado um componente teórico fundamental na teoria social e política (s).

A teoria política feminista conduz os debates sobre democracia, participação, representação, esfera pública, autonomia, identidade, Estado, dentre outras questões do campo político, partindo da constatação que a separação das esferas pública e privada reproduz as relações de poder que oprimem e excluem as mulheres ou, ainda, as colocam em situações de desigualdades frente aos privilégios masculinos.

O feminismo promove a redefinição da teoria política e da teoria social ao colocar em xeque a neutralidade de categorias consagradas nesses campos teóricos, que se estabeleceram, até então, a partir de um caráter universal, invisibilizando e excluindo as questões da esfera privada e doméstica que estão diretamente relacionadas às mulheres, distanciando-as do acesso à cidadania $\mathrm{e}$ à justiça social. A teoria feminista vem reforçar que as transformações sociais nas relações de gênero, classe e raça, somente serão possíveis se houver mudanças nas relações hierárquicas e opressoras da esfera pública.

A teoria crítica feminista fortalece a luta das mulheres enquanto sujeito político de direitos, que se materializa pelo direito à fala, à terra, à água, ao território, no acesso às políticas públicas e no processo de autodeterminação de seus corpos, na luta por autonomia, na construção de outras formas de economia, pelas relações de solidariedade, reciprocidade, pela prática do cuidado, amorosidade e sororidade, pela construção de outros mercados, no reconhecimento dos bens comuns como indispensáveis à vida, à natureza como nossa mãe e irmã, aos saberes descolonizados e ecológicos e assim, na luta contra todas as formas de violências.

Entendemos que a transformação social só poderá ocorrer de forma eficaz, via processos educativos, populares e coletivos. Para tal, é fundamental que nós mulheres consigamos transformar o conhecimento existente sobre nós mesmas e sobre a realidade a partir das lentes dos feminismos, das nossas experiências e especificidades, criando e nos apropriando de métodos e procedimentos que se aproximem da nossa maneira de ser e estar no mundo. "Hacia una pedagogía feminista"!

Corroboramos com Claudia Korol (2007) ao afirmar que para se construir uma pedagogia feminista é necessário desorganizar as relações de poder de forma subversiva e revolucionária, considerando o valor da subjetividade na criação histórica e o valor dos corpos inscritos nos territórios. A pedagogia feminista bebe da fonte da pedagogia popular - que parte da educação como prática de liberdade (FREIRE, 1999) - e do feminismo, se constitui ao assumir o enfrentamento às estruturas opressoras, mas também em construir formas de resistências. Para a construção dos materiais e meios necessários, se faz urgente o conhecimento das histórias das mulheres, pois, "a valorização das várias vozes, sendo o diálogo sua dinâmica problematizadora, no qual todas e 
todos são igualmente falantes e ouvintes, capazes de expressar diferente saberes" (SANTOS; BONFIM, 2010, p. 2), possibilita a conscientização da sua posição no mundo.

\subsection{A pedagogia feminista do projeto ATER, Feminismo e Agroecologia}

O processo de aprendizado durante este projeto (2014-2017) nos desafiou tanto como universidade, quanto como movimentos sociais e organizações não governamentais em nossas práticas cotidianas, nos levando a reconhecer a emergência de outras narrativas, a partir de novas perguntas, contribuindo para a construção coletiva do conhecimento. Assim, a importância da construção deste projeto/processo se deu pela proposta educativa e das possibilidades de diálogos entre os diferentes atores ${ }^{12}$ - Estado, universidades, organizações governamentais e não governamentais, movimentos sociais, assessoras técnicas e mulheres rurais-, que nos desafiam enquanto mulheres feministas, a partir dos distintos lugares de atuação e de enunciação. Partindo das nossas trajetórias, das formas de sentir no mundo e de lutas e conquistas, a pedagogia feminista privilegia as micro-dimensões sociais e individuais com o intuito de alçar reflexões e transformação na dimensão macrossocial e coletiva.

Entendemos que a "ciência ou o conhecimento formal" foi durante muito tempo negado às mulheres e os seus saberes/fazeres e a construção do conhecimento gerado por elas foi e ainda é historicamente invisibilizado e/ou desvalorizado, sendo reconhecido como crendices ou ainda práticas culturais tradicionais. Desta forma, se enquadram todo o conhecimento do manejo de plantas medicinais, das ervas sagradas e de poder, das parteiras, raizeiras, curandeiras, do cuidado, da criação de pequenos animais, das outras formas de produção e economia, etc. Urge reconhecermos esses saberes como imprescindíveis à reprodução da vida e toda a contribuição das mulheres às práticas agroecológicas, como forma de complexificar os processos de transição agroecológica e reafirmar nosso entendimento da agroecologia enquanto ciência, movimento e prática.

Um primeiro exercício coletivo entre nós foi a afirmação de que o que sabemos é importante, que todo o conhecimento é de ordem distintas de saberes e que tem valor e é complementar. Todo conhecimento, seja acadêmico ou empírico; seja das práticas cotidianas ou científico/tecnicista é vivenciado nos corpos e nos sentidos mais tênues de nós mulheres. Todos eles são indispensáveis para a reprodução da vida e esse exercício feminista, de nos enxergar como iguais em direitos, porém distintas, fez com que pudéssemos

12 Participaram 22 organizações não governamentais, 2 universidades e 4 movimentos sociais (Movimento dos Trabalhadores Rurais Sem Terra - MST, Movimento da Mulher Trabalhadora Rural do Nordeste - MMTR-NE, Movimento da Mulher Trabalhadora Rural do Nordeste MIQCB e Movimento dos Pequenos Agricultores - MPA). 
construir o conhecimento coletivo neste projeto/processo com toda nossa diversidade e complexidade.

Foram vários os limites e os desafios neste exercício do trabalho coletivo, de tessitura e de consensos conflitivos na construção desta experiência. No entanto, a oportunidade que tivemos de nos debruçar sobre esta importante política pública, sobretudo, com as mulheres rurais e as assessoras técnicas (que normalmente estavam presas às burocracias da execução da política), e refletir sobre os processos e as práticas políticas-metodológicas que abarcassem outras formas de efetivar uma ATER Feminista e Agroecológica para além dos marcos institucionais, foi o que nos animou e moveu como Rede.

Entendemos que é urgente um olhar crítico a partir da teoria feminista descolonial, que valorize os diferentes saberes, conhecimentos, experiências e práticas das mulheres, assim como seu protagonismo na construção da agroecologia na Região Nordeste do Brasil. Buscamos trazer para o campo agroecológico a importância e a convergência positiva (como potência geradora de transformações) entre os feminismos e a agroecologia, no qual compreendemos como um projeto de vida (a retomada de um outro modelo de desenvolvimento), para além de um processo de conversão produtiva.

A agroecologia deve promover a mudança de valores éticos, morais, epistêmicos em que mulheres, jovens, homens, natureza, sejam reconhecidos como sujeitos integrantes de um todo complexo e complementar na construção de outro modelo de sociedade. Questionamos não a agroecologia como prática em si, mas a ideia normativa do que venha a ser, ou do que dever ser ditada por homens quase sempre brancos na disputa por conceitos e categorias científicas, e que, historicamente, deixa de fora essa complexidade de questões e de sujeitos. Para o movimento feminista e agroecológico, o questionamento a essa normativa surge da exclusão histórica das mulheres e de outras narrativas e do questionamento a uma ciência branca, colonizadora, machista e patriarcal.

Essa é uma lente de abordagem teórica no questionamento à ciência androcêntrica e cartesiana, mas também de ação política no reconhecimento das mulheres como construtoras de conhecimento e portadoras de saberes indispensáveis para a reprodução da agroecologia e do campesinato, que nos leva a repensar questões e construir instrumentos metodológicos que deem conta desta proposta e dialogue com as distintas realidades.

Por meio das diferentes ferramentas metodológicas que foram sendo "experimentadas", buscamos compreender, aprender, e comunicar/divulgar recomendações às políticas de ATER operacionalizadas pelo Estado via chamadas públicas, a partir da perspectiva crítica dos feminismos e da educação popular. Também contribuir para a construção da autonomia das mulheres, tanto na dimensão produtiva, quanto na dimensão política, social e cultural. Priorizamos problematizar em relação às ações da ATER e suas metodologias utilizadas, o questionamento à divisão sexual do trabalho, a desvalorização e a 
invisibilidade do trabalho doméstico e do cuidado e das atividades que são desenvolvidas pelas mulheres (na casa e no agroecossistema ${ }^{13}$ ). Tais dimensões também são apontadas pelas chamadas como eixos fundamentais para o fortalecimento e autonomia das mulheres rurais.

Neste sentido, iniciamos com algumas questões problematizadoras e dimensões que nos poderiam ampliar novos olhares e alternativas outras, tal como, refletir nossas próprias práticas:

- Divisão sexual do trabalho na agricultura familiar: Quais os espaços que as mulheres e homens protagonizam no agroecossistema? O que é trabalho produtivo versus reprodutivo? É normal só a mulher ser responsável pelo trabalho doméstico, pelo cuidado com as crianças e idosos e pela educação? O que significa o trabalho "leve" e a "ajuda" na agricultura familiar? Por que o trabalho da mulher ainda é invisibilizado e desvalorizado? Quais as condições enfrentadas pelas mulheres no seu processo de organização produtiva? Como as violências cotidianas sofridas pelas mulheres se expressam nessa dicotomia entre trabalho produtivo versus reprodutivos?

- Relações de gênero e participação política: Quais são os espaços que as mulheres e os homens estão assumindo hoje? As mulheres estão protagonizando os espaços políticos de participação - sindicatos, conselhos, feiras, etc. E como seu conhecimento é, ou não valorizado? Quais as condições enfrentadas pelas mulheres no seu processo de organização política?

- Entendimento da Assistência Técnica prestada como um serviço do Estado e suas possibilidades: Qual o tratamento da ATER a temas emergentes (democracia, conflitos agrários, racismo, sexismo, violência contra as mulheres)? Como a política pode avançar no reconhecimento e promoção das relações igualitárias entre os homens e mulheres e das diferentes identidades sexuais? Qual o papel dos/as assessores/as técnicos/técnicas? Como a política se coloca frente às situações de violência e racismo? E em relação à sobrecarga do trabalho das mulheres? Quais os avanços e os limites que ainda existem para a ATER Agroecológica se constituir como uma política que questione as bases do patriarcado e do machismo? O que é diferente de uma política setorial "para mulheres"? Como a política torna-se um direito das mulheres rurais?

13 "O agroecossistema é definido como um tipo específico de ecossistema modificado pela ação humana por meio das atividades agrícolas. É a unidade geográfica delimitada (ainda que variável quanto a sua extensão) onde se dão complexas relações entre práticas agrícolas e o ecossistema original. Para se entender essas relações é necessário analisar não apenas os fenômenos ecológicos que ali ocorrem (bioquímicos, agronômicos), mas também as interações entre os seres humanos" (SILIPRANDI, 2009). 
Como passar de "inclusão discursiva" nos programas públicos para a "inclusão efetiva"?

Neste processo, a pedagogia feminista nos deu base para apreender os olhares para a política pública a fim de refletir sobre as relações de conflito, desafios, potencialidades, impactos e aprendizados da ATER para as mulheres agricultoras e assessoras técnicas nas diferentes dimensões que estão envolvidas no arranjo institucional da política, bem como essas mudanças e aprendizados foram sendo acumulados como processos educativos para as organizações executoras das chamadas públicas.

\section{Metodologias Feministas para Pensar a Política Vivida}

Nós, mulheres participantes vimos nesse projeto a chance de refletir sobre os velhos e novos desafios presentes na PNATER, além de dar oportunidade de buscar "fazer diferente", tanto por parte da reflexão sobre o desenvolvimento da agroecologia nos territórios como também, o reconhecimento da atuação das mulheres como protagonistas nesse campo. A preocupação foi com a maneira de desenvolver processos de construção do conhecimento e de intervenção junto às mulheres rurais que pudessem ser propulsores de geração de autonomia nos seus territórios, contemplando as nossas angústias (apresentadas anteriormente, como também provocar mudanças institucionais, sobretudo metodológicas nas organizações executoras das chamadas.

$\mathrm{Na}$ construção do projeto/processo buscou-se problematizar as práticas acadêmicas, atrelando às práticas de movimentos sociais e de organizações do terceiro setor, reconstruindo questionamentos e elaborando alternativas através do escopo teórico-metodológico embasado na auto-organização das mulheres e no feminismo.

Neste processo/projeto aprendemos que equalizar os distintos tempos era um grande desafio: o tempo do Estado; o tempo das universidades, o tempo das organizações e movimentos sociais... precisávamos reaprender a construir coletivamente e desta forma, criar um tempo do projeto/processo que fosse a conciliação destes distintos tempos. E esse aprender também norteou todo o processo metodológico e pedagógico para a construção de caminhos e alternativas para a execução em si e que refletisse a complexidade das questões, a partir das diferenças territoriais e organizacionais.

Esse fazer diferente no processo de aprendizado nos aproximou e nos articulou, sendo somente possível em virtude de uma pedagogia feminista presente na construção coletiva de metodologias para pensar uma ATER feminista, agroecológica, despatriarcal, antirracista, descolonizadora. Regadas por momentos de vivências subjetivas e corporais, nos aproximando pelas dores das opressões sentidas, escutadas e acolhidas, mas também, pelos estímulos aos afetos e momentos místicos ricos de significados, fomos construindo 
diversas atividades que respondiam aos objetivos trazidos durante a execução do projeto/processo. Assim, nasceram as propostas de seminários de formação, as oficinas locais nos territórios, a sistematizações de experiências, a cartografia social e feminista, campanha educativa como outras formas de linguagem.

\subsection{Seminários de formação}

Ao longo dos três (03) anos do projeto foram realizados seis (6) Seminários regionais, se configurando em significativos espaços de formação e construção do escopo que se tornou a riqueza do projeto/processo: a construção coletiva feminista. Os temas eram transversais e problematizadores das atividades de "ATER, Feminismo e Agroecologia", como Estado; políticas públicas; Violências e conflitos territoriais; Gênero; Economias; Mercado; Segurança e soberania alimentar; Trabalho de cuidados; Divisão sexual do trabalho; dentre outros.

O local de realização das atividades centrais do projeto ocorreu em Recife-PE, em virtude da localização geográfica da cidade contemplar a chegada das mulheres dos diferentes estados do Nordeste, aliando-se a isto a viabilidade da gestão do projeto através da execução dos orçamentos. Os Seminários ocorreram no mesmo local de hospedagem e alimentação, garantindo uma convivência diária entre nós, que além dos momentos de construção do projeto/processo compartilharam dormitórios, refeição, lazer e descanso. Os Seminários aconteciam em média de três dias, considerando tempo de chegada das mulheres de todos os estados e sua necessidade do retorno para casa.

As propostas de programação eram construídas coletivamente e abordavam temas relacionados às vidas das mulheres e suas experiências nos territórios, problemas na execução da política de ATER, percepções sobre a política a partir das mulheres rurais e das assessoras técnicas, as questões políticas, violência e etc, sempre desenvolvendo trabalhos em grupos, discussão em plenária, elaboração de sistematização e relatoria (para guardar a memória do processo/projeto). Tudo isto perpassado pelos momentos de vivências corporais, místicas e atividades culturais e de lazer. Para algumas mulheres eram momentos de construção e fortalecimento de laços, para outras, verdadeiras descobertas e experimentações de lazer, saberes e convivência nunca antes vivenciadas; ao mesmo tempo em que nos possibilitava relaxar do cotidiano de trabalhos, obrigações e sobrecargas cotidianas.

As místicas e os afetos foram aspectos que marcaram o desenvolvimento de todo o projeto, incentivando a proximidade entre nós, através das convivências e construção de vínculos e desenvolvimento de outras racionalidades e sensações. Nesse sentido, as programações dos seminários e demais atividades previam atividades coletivas, através de cirandas, cantos, poesias, danças, teatro, estímulos as memórias ancestrais das mulheres e os afetos. Já no primeiro Seminário foram realizados momentos de dança circular, 
meditação, carícias e Biodança ${ }^{14}$; elementos que se repetiram de diferentes maneiras ao longo de todo projeto, nos aproximando e criando laços de afetos e sororidade. Claudia Korol afirma que esses momentos são necessários no trabalho com mulheres como parte de uma pedagogia feminista.

\begin{abstract}
¿Se puede hablar de la caricia como parte de una metodología de investigación o de análisis? No tengo dudas de que el abrazo y la caricia, el reconocernos en una mirada, el sentirnos en una piel, producen posibilidades de "conocimiento" tanto o más fecundas que otras formas de estudio o de investigación. No me refiero a la caricia programada, ni al abrazo paternalista realizado desde un lugar de saber o de poder, de contención 0 de sostén. Me refiero a la caricia y al abrazo que nacen en el momento exacto del encuentro de las historias de opresiones que nos identifican. La caricia y el abrazo que forman parte de una ética feminista del acompañamiento, del caminar codo a codo, de transitar los dolores y hacernos cómplices de nuestros deseos (KOROL, 2007, p. 20)
\end{abstract}

Contávamos com espaços de vivência para silenciar, desabafar, descarregar o cotidiano de trabalho e de opressões vivenciadas no trabalho, na militância, em casa e na rua, compartilhando da certeza de que sairiam fortes e renovadas. Muitos desses momentos se configuravam em espaços místicos, onde traziam à tona o respeito à diversidade étnica e religiosa e proporcionavam trocas energéticas para acolhimento e renovação.

Os símbolos de representatividades dos grupos de mulheres, movimentos, produção artesanal e agroecológica, reminiscência indígena e quilombola, materiais institucionais, bandeiras, formavam verdadeiras instalações artísticas pedagógicas no centro da sala onde aconteciam as atividades. Este cenário simbólico contribuía para um reconhecimento coletivo do saber-fazer, revelando não apenas as bandeiras de lutas, mas também, nossos os desejos, sonhos, identidades, habilidades e discursos.

Essas instalações se configuravam em Feira de saberes e sabores com produtos da agricultura familiar de base agroecológica e da economia solidária: sementes crioulas, mudas de plantas, azeites de coco babaçu e outros derivados, artesanatos diversos, além da socialização das produções impressas sobre sistematizações de experiências institucionais com: cartilhas, folders, Dvds, livros, dentre outros.

14 Biodança é um sistema de integração humana, renovação orgânica, reeducação afetiva e reaprendizado das funções originárias da vida. Sua metodologia consiste em induzir vivências integradoras por meio da música, do canto, do movimento e de situações de encontro em grupo. Ver: https://www.biodanza.org/pt/biodanza/definicion-de-biodanza. 
Trocar era o verbo praticado pelo nosso coletivo, socializando saberes, sabores e ousando simbolizar a união, não apenas na prática da construção de uma rede em processo de fundamentação ou nas vivências objetivas dos encontros, mas, de forma simbólica, como a distribuição dos anéis de Tucum pelas mulheres indígenas da etnia Xucuru do Ororubá, durante o último seminário. Todas as mulheres receberam os anéis simbolizando a aliança entre si, um marco simbólico do nosso encontro, que pautava a agroecologia, a igualdade entre mulheres e homens, a não violência contra as mulheres, uma ATER emancipadora e que promova uma real divisão justa do trabalho doméstico.

A doação também se fez presente nessa experiência pedagógica. Cada uma ofertava o que tinha, como queria e podia. Essas doações além de saberes e afetos eram também energéticas, algumas vezes relacionadas à espiritualidade. O exemplo disso aconteceu antes de iniciar o V Seminário, onde foi realizado o Corredor de Cura, facilitado pela agricultora agroecológica e feminista negra Luisa Cavalcanti, do Sítio Agatha, Tracunhaém -PE. Foram organizadas duas filas uma de frente para outra, como um corredor, enquanto que cada uma de nós entrava de olhos fechados e as outras Ihes diziam palavras (de amor e estímulo) em voz alta ou no ouvido, Ihe abraçavam, beijavam, massageavam, o que cada uma sentia no peito e na alma era doado. Quem passava no corredor vivenciava uma experiência sensorial, de confiança, de afeto, descarrego e de benção espiritual, para citar algumas das impressões socializadas sobre o ritual.

Além das pautas políticas, entoávamos através de cantos as resistências territoriais onde todas assumiam as lutas de cada uma, representada aqui na letra da música das quebradeiras de coco babaçu, que embalaram as cirandas de composição de debates.

\author{
Ei! Não derruba esta palmeira \\ Ei! Não devora os palmerais. \\ Tu já sabes que não pode derrubar, \\ precisamos preservar as riquezas naturais. (refrão) \\ (Encantadeiras e quebradeiras de coco babaçu. Movimento \\ Interestadual das Quebradeiras de Coco Babaçu - MIQCB)
}

Ao criar uma atmosfera confortável na aceitação de si e na construção coletiva do saber-fazer feminista, este tempo das mulheres reconhecido possibilitou o desenvolvimento, alinhamento e a qualificação de nossas metodologias ao longo do projeto/processo.

Fotografia 1 - I Seminário do projeto/processo - "Biodanza" 


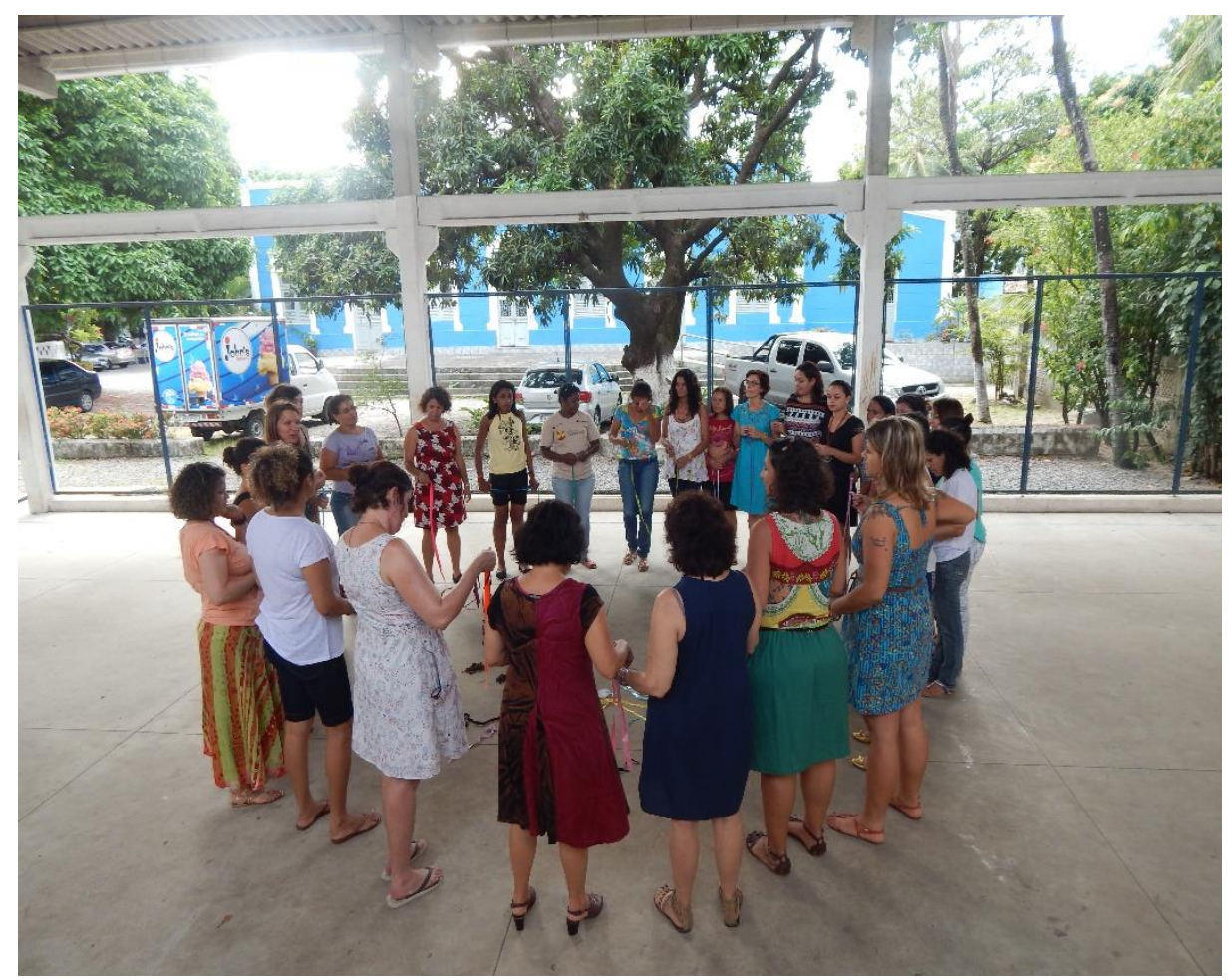

Fonte: Acervo Rede Feminismo e Agroecologia

O primeiro Seminário teve como foco construir a proposta do projeto, os objetivos e ações a serem desenvolvidas. Foi no processo de construção que o aprendizado também se mostrava na edificação dos nossos desejos e das demandas territoriais. Era a cada encontro que as etapas seguintes iam sendo tecidas, chegando aos primeiros seminários a pergunta: e "o projeto? Mas que projeto? O nosso projeto! E assim foi sendo construído o projeto/processo".

O segundo seminário foi pautado ainda pela discussão daquilo que precisávamos definir como metas próprias para construir e realizar em seus territórios e organizações, a partir das ações que já vinham desenvolvendo. Entendíamos que não podíamos sobrecarregar as assessoras técnicas de novas demandas e sim, repensar a partir das metodologias e práticas que já vinham desenvolvendo na execução das chamadas públicas. Este seminário foi fundamental para o aprofundamento das questões levantas sobre a ATER e a vida das mulheres rurais, dando atenção a essa relação para construir horizontes a priorizar.

O terceiro seminário teve como principal objetivo dar continuidade ao planejamento as propostas desenvolvidas durante os Seminários I e II, com destaque para o aprofundamento das oficinas de Sistematizações de Experiências, incluindo a Cartografia Social e a Campanha Educativa. Contudo, a programação também garantiu outras atividades de formação com as participantes, que precisaram refletir sobre o que plantava e o que colhiam do seminário?! Como forma de avaliar, como atividade do meio do processo, as 
necessidades de trazer a contribuição de cada uma e sua expectativa sobre o projeto.

O quarto seminário aconteceu em dezembro de 2015. O projeto/processo nesse período já tinha avançado nas formações e na construção das peças pedagógicas, sendo este momento voltado para acompanhamento das Sistematização das Experiências de ATER, construção coletiva da Cartografia, apresentação e ajustes da Campanha Educativa, todas endossadas com o tema gerador deste Seminário, que permeou a reflexão da Leitura de Conjuntura: A política na Vida das Mulheres Rurais ${ }^{15}$, cumprindo a necessidade daquele momento de compreendermos juntas a conjuntura de Golpe que se desenhava contra a presidenta Dilma Rousself, tendo impactos diretos para a vida das mulheres.

O V Seminário inaugurou um cenário diferente para nós, mulheres integrantes do projeto. Era chegada a hora de colocar "o bloco na rua" ocupando a universidade para falar de ATER, Agroecologia e Feminismo. O debate gerador era sobre as Políticas Públicas para mulheres rurais, tendo como foco os desafios da ATER. Se junta a essa ciranda de mulheres a organização do II Seminário de Mulheres e Agroecologia, com o tema "Juntas Transformando Políticas Públicas". Esse Seminário foi voltado não apenas para as participantes do projeto, mas também para estudantes, professoras e demais mulheres de movimentos sociais afins. A programação foi construída com atividades para as mulheres do projeto/processo e para as demais participantes do seminário, possibilitando as mulheres adentrar ao ambiente acadêmico com suas pautas e experiências individuais, comunitárias e profissionais. Oficinas de construção da Cartografia, quintais produtivos e segurança alimentar foram realizadas conformando as ações preparatórias para a Conferência Nacional de ATER CNATER, assim como o lançamento de livros e noite cultural, marcando três dias de atividades intensas.

O VI último Seminário teve como tema Mulheres em Territórios de Resistência - Lutas e Construções Feministas por uma ATER Agroecológica e foi a celebração de toda a construção do nosso projeto/processo. Momento de trazer para a roda as questões das mulheres apresentadas nas peças pedagógicas. Os sujeitos políticos sistematizados nas cartilhas, na sistematização das experiências, na Campanha educativa, denunciando os impactos sofridos pelo machismo, racismo e capitalismo, ao mesmo tempo em que dava visibilidade a sua contribuição na construção da sociedade igualitária, na agroecologia. Debates focados na violência contra a mulher, racismo, bem como os protagonismos das mulheres pescadoras que enfrentam experiências de impactos nas suas vidas e nos territórios foram recorrentes.

15 Momento facilitado por Laetícia Jalil (UFRPE/PE) e Conceição Dantas (MMM/CF8/RN). 
A celebração desse percurso de três anos contou com uma sistematização da consolidação do projeto/processo pelas coordenadoras do projeto; debates sobre divisão sexual do trabalho; lançamento da Campanha com entrega dos materiais pedagógicos, e lançamento do vídeo da Cartografia Feminista como experiências que nos comprometeram a continuar tecendo os laços de amizades e lutas.

3.2 Cartografia Social: "No tempo das mulheres - a experiência da Cartografia Feminista no contexto da Assistência Técnica Rural".

Entre as metodologias utilizadas, a Cartografia Social ${ }^{16}$ foi a que se destacou por nos fazer identificar, dar visibilidade e refletir sobre as diversas experiências de ATER para mulheres nos distintos territórios da Região Nordeste, procurando visibilizá-las, desenhá-las em novos mapas, a partir da compreensão que são expressões de resistências. A cartografia é técnica de construir mapas como representações da realidade nos territórios, e estes mapas se transformam em "representações oficiais" se configurando em mapas tradicionais dos territórios, que invisibilizam diversas outras formas de viver, construir e disputar estes espaços. Os mapas tradicionais se apresentam de forma neutra e sem movimento, desconsiderando a expressão das especificidades, suas dinâmicas e, sobretudo, seus sujeitos e sujeitas, que são a todo tempo os que constroem e reconstroem o espaço (UFRPE, 2017a).

Além de conseguir identificar os desafios e bandeiras de lutas em comum, enfrentados pelas mulheres nos diferentes estados do Nordeste, foram necessários quatro (04) momentos distintos para a construção da Cartografia Feminista que possibilitou mapear organizações feministas e mistas do campo da agroecologia, movimentos sociais e principais eixos temáticos relacionados às opressões e representações de autonomia das mulheres.

No primeiro momento foi socializado de forma conceitual a Cartografia Social, sua utilização e importância para a autoidentificação como estratégia de construção de autonomia. No segundo momento, identificamos o que nos unia com fitas de cetim coloridas para cada dimensão que impactava nossas vidas de forma positiva ou negativa (conflitos territoriais, violência de gênero, experiências agroecológicas e da economia solidárias, grupos de mulheres etc). Assim, a instalação mística no centro do espaço físico dos Seminários foi criada a partir dos seus símbolos, da produção artesanal e agroecológica, de materiais de divulgação dos seus trabalhos. Noutro momento, foram realizados trabalhos em grupos por estado para a feitura de desenhos de mapas e símbolos que

16 "A cartografia social constitui-se como um ramo da ciência cartográfica que trabalha, de forma crítica e participativa, com a demarcação e a caracterização espacial de territórios em disputa, de grande interesse socioambiental, econômico e cultural com vínculos ancestrais simbólicos" (GORAYEB; MEIRELES, 2014). 
representassem as atuações, organizações e movimentos sociais ali representados.

Na última atividade, nos lançamos à versão final de um mapa do Nordeste com medidas para construir juntas aquela que hoje é a Cartografia Social Feminista $^{17}$, através da prioridade de problemáticas enfrentadas pelas mulheres agricultoras, militantes, professoras, técnicas no campo do feminismo e da agroecologia no NE. Esta oficina da construção da Cartografia reuniu uma diversidade de saberes e experiências, onde pudemos empregar através das pinturas, dos bordados, dos fuxicos, cortes e costuras, as várias formas de opressão e as resistências essenciais para contribuir com a emancipação feminista.

A Cartografia Social Feminista construída neste projeto/processo é parte de uma inovação na produção do conhecimento, pois, questiona a dominação dos instrumentos e saberes cartográficos, ousando o saber-fazer o próprio mapa a partir do conhecimento dos seus territórios (UFRPE, 2017a). Alimentamos o processo/projeto de construção da cartografia e produção de mapas, que não são pautados de uma leitura dominante de um território, mas sim de um caminho, desde a vida das mulheres e desde o feminismo. Subvertendo as fronteiras "oficiais", isso significa cartografar a própria vida, a subjetividade e dar conta dos movimentos de transformação, que marca a luta das mulheres e suas práticas no presente em distintos territórios vividos (UFRPE, 2017a).

\subsection{Sistematização das experiências de ATER feminista na região}

Nordeste (experiências que antecedem às exigências das chamadas públicas):

A Sistematização das Experiências foi mais um dos processos de formação que vivenciamos, trazendo a novidade da elaboração de textos que contassem as metodologias utilizadas pelas assessoras técnicas e instituições de ATER, sejam de organizações feministas ou mistas. O desejo coletivo era de registrar as metodologias de ATER na perspectiva do feminismo que já estavam sendo construídas pelas organizações e que pudessem servir de inspiração para outras organizações executoras de ATER.

A sistematização dessas metodologias pelas assessoras técnicas possibilitou o desafio delas olharem para a prática institucional e para sua própria prática cotidiana na ATER, bem como considerá-las como sujeito político de construção do conhecimento da assistência técnica e extensão rural, da agroecologia e do feminismo. Este trabalho resultou em um livro que reúne as 
experiências de 13 organizações e movimentos sociais feministas e mistos de 04 estados do Nordeste.

A partir da pedagogia feminista construímos as orientações coletivas para as sistematizações, definindo o roteiro para trazer a situação do antes e depois do acompanhamento: Cenário local antes da assessoria técnica feminista? Como aconteceu o processo? Quem fez? Como fez? Os avanços e as mudanças, principais aprendizados e recomendações à política pública.

As assessoras técnicas fizeram o exercício de desenvolver juntas às mulheres rurais e à equipe técnica da ATER em seus territórios, em formato de oficinas, para dar conta de refletir sobre a prática da organização e a sua própria prática. A "construção feita a muitas mãos", passa pelo campo do que acreditamos e queríamos mostrar nesse processo de registro da construção do conhecimento.

\begin{abstract}
Decidimos que temos o que mostrar, e que a diversidade de experiências deve ser visibilizadas como práticas metodológicas que podem ajudar a pensar o processo de construção do conhecimento agroecológico e fortalecer a ATER como uma política integradora de outras políticas públicas, uma "porta de entrada" que colabora para dar novo sentido a vida nos territórios, em que as mulheres são reconhecidas como sujeitos políticos. (UFRPE, 2017b).
\end{abstract}

Este foi mais um processo de identificação das experiências de assistência técnica de organizações mistas e feministas, que tomam por base os princípios da agroecologia e o referencial feminista na sua atuação. A esta estratégia incluímos aquelas experiências anteriores às chamadas públicas de ATER, fazendo emergir a atuação de assessoras técnicas e organizações comprometidas com a defesa dos direitos das mulheres antes mesmos das políticas públicas específicas.

Figura 1 - Capa da publicação da sistematização: ATER Mulheres - Autonomia e luta: experiências de metodologias feministas (2017)

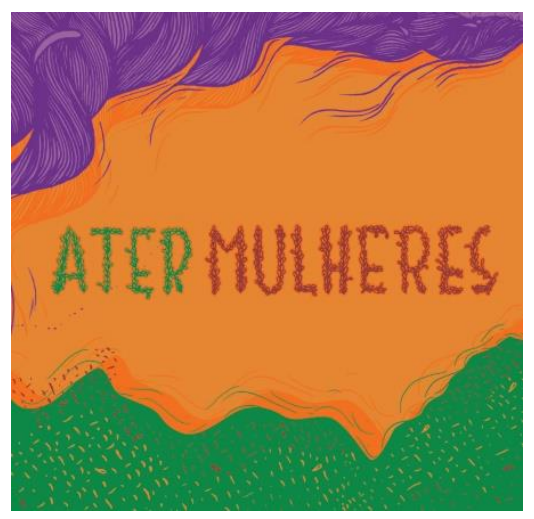

Fonte: Acervo Rede Feminismo e Agroecologia 


\subsection{A Campanha educativa: "Pela Divisão Justa do Trabalho Doméstico:}

Direitos são para mulheres e homens, responsabilidades também"

Diante do processo de construção do projeto e da possibilidade de criar a partir de uma leitura crítica sobre a realidade foi decidido pela criação de uma Campanha Educativa ${ }^{18}$, de cunho político e pedagógico.

Assim como tivemos a autonomia para definir (coletivamente) por quais caminhos seguir frente à definição dos produtos e atividades executadas no projeto, também tivemos a liberdade para escolher o tema que a campanha educativa iria interpelar. Em um coletivo de mulheres que exalava diversidade, foi unânime a decisão pela necessidade de discutir sobre a "divisão justa do trabalho doméstico", cujo tema se apresentou como uma problemática cara a todas nós, independente de classe, raça, territorialidade e geração.

No marco da discussão sobre a assistência técnica agroecológica para mulheres rurais, na perspectiva do feminismo, perguntou-se qual era um dos maiores impeditivos para que as mulheres rurais acessassem outras políticas e projetos, participassem de cursos, intercâmbios, seminários, até mesmo de associações ou sindicatos. $E$ a resposta foi unânime: $O$ acúmulo das tarefas domésticas! Não ter com quem deixar os filhos ou idosos ou qualquer outra pessoa que estivesse sobre seus cuidados. Fazer a alimentação, lavar roupa, passar, limpar casa, terreiro, cuidar dos pequenos animais, fazer remédios, etc. Era comum o relato de que para saírem de casa, tinham que levar os filhos/as ou voltar antes deles/as chegarem da escola. Concluiu-se que a (injusta) divisão sexual do trabalho doméstico ainda se constitui como um forte impeditivo, ou uma grande barreira às mulheres para a conquista de seus direitos, autonomia e cidadania plena.

A Campanha se constituiu de forma coletiva através de grupos de trabalhos nos três Seminários, problematizando o tema do trabalho doméstico; estratégias de comunicação; criação de mensagens reflexivas; de possíveis mudanças de comportamentos a serem impactados, locais para realizar a divulgação, etc. e foi materializada para as mulheres rurais e urbanas, convocando os homens e o restante da família (filhos/as, parentes e agregados) para a divisão das responsabilidades domésticas e do cuidado, de forma crítica e propositiva. As peças da Campanha estão se transformando em marcos simbólicos da construção coletiva e da luta feminista nos territórios de resistência da Região Nordeste, principalmente.

A Campanha teve seu primeiro lançamento durante o VI Seminário de formação do Projeto "ATER, Feminista e Agroecologia", realizado em março de

18 Como peças da Campanha "Pela Divisão Justa do Trabalho Doméstico", foram produzidos cartazes, panfletos, spots de rádio, rádio novelas, bolsas e camisetas e um vídeo animação, que estão sendo utilizados nos territórios, em feiras locais e nos eventos promovidos pelas organizações que fazem parte do projeto. 
2017, e desde então tem sido apresentada em diversos territórios nordestinos, aqueles identificados na Cartografia Feminista, multiplicando a discussão da divisão justa do trabalho doméstico para feiras, rádios, escolas, universidades, sedes de sindicatos de trabalhadores e trabalhadoras rurais, conselhos municipais, associações de moradores, postos de saúde, federação de trabalhadores/as rurais, movimentos sociais e organizações não governamentais. A Campanha também foi apresentada durante o $14^{\circ}$ Encontro Latinoamericano e do Caribe em Montevidéu, Uruguai e no Fórum Social Mundial de 2018.

É perceptível que a divulgação da Campanha em todos os territórios nos nove estados do nordeste do Brasil e mesmo em eventos internacionais, tem reforçado o tema da divisão justa do trabalho doméstico com muita potência, mostrando como antigos debates ainda devem ser discutidos tanto na academia, nos movimentos sociais, feministas e mistos e das organizações de ATER, para que de fato a política pública de ATER seja um instrumento de transformação da realidade das mulheres rurais e contribua para um processo de desenvolvimento rural democrático, solidário e feminista.

Logo da Campanha

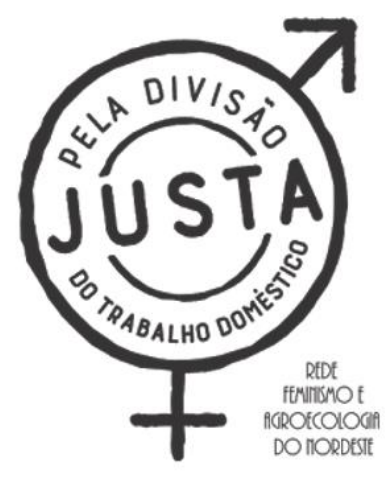

VI Seminário ATER, Feminismo e Agroecologia Lançamento da Campanha Pela Divisão Justa do Trabalho Doméstico - 2017

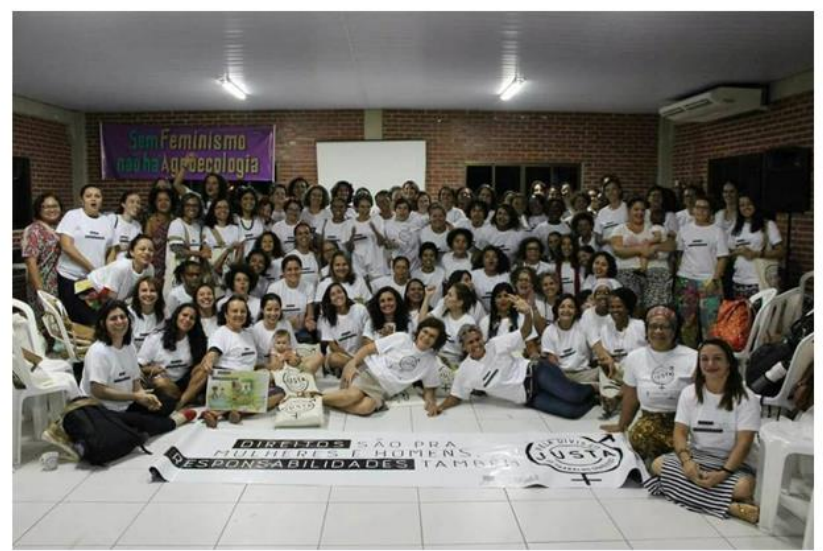

Fonte: Acervo Rede Feminismo e Agroecologia

\section{O que plantamos, o que colhemos e o que compartilhamos...}

Essa forma ousada de refletir sobre os desafios, apontar alternativas para a superação das desigualdades, sugerir modos de executar a política pública com e para as mulheres rurais, proporcionou um híbrido resultado dessa experiência: um projeto que teve como desdobramento um processo de construção de conhecimento e de junção das sabedorias feministas para 0 campo da agroecologia, especialmente na Região Nordeste.

Apostamos nestes caminhos epistêmicos da pedagogia feminista e nestas ferramentas metodológicas pelo seu caráter participativo (do escutar, sentir, vivenciar e refletir coletivamente), que possibilitou alcançar uma comunicação 
reflexiva entre todas, como do poder de enunciar os saberes localizados das mulheres a partir de suas realidades corpo-territórios. A formação política e feminista nos constitui enquanto sujeito da transformação social e reflexiva, não como sujeitos individuais, mas sim, como sujeitos políticos diante do processo coletivo de mudanças na vida das mulheres.

Uma das prioridades deste coletivo foi valorizar os conhecimentos das mulheres; de visibilizar experiências, anteriores ao marco da ATER setorial Mulher e Agroecológica pelo Estado; de realizar uma autocrítica e sair do lugar comum para repensar a própria prática das organizações não estatais e dos movimentos sociais: suas dificuldades, desafios, limites e avanços ao longo das últimas décadas; que trouxesse elementos para orientações de como avançar a Política Nacional de ATER, possibilitando o real fortalecimento das mulheres, assessoras/es técnicas/os e dessas organizações em seus territórios.

Nos desafiamos na elaboração de propostas metodológicas que favorecessem a construção de conhecimentos mais dialógicos e crítico, que criassem brechas para uma "ecologia de saberes" entre assessoria técnica técnica/o (educadora), mulheres rurais, pesquisadoras e acadêmicas; voltadas para compreender as demandas específicas das mulheres rurais, do esforço para construir relações menos hierárquicas, problematizar o fazer agroecológico, fortalecer os processos locais de resistências e reconstrução dos territórios (como espaços de disputas e lutas) e o reconhecimento das mulheres como sujeitos políticos, portadoras de saberes e práticas imprescindíveis para a reprodução da vida.

Acreditamos que o projeto/processo a partir da pedagogia feminista nos trouxe perspectivas e horizontes para continuar a construir novos caminhos, outros modos de fazer, criar e comunicar nossas lutas, saberes, metodologias, tal como compreender os desafios vivenciados neste campo de ação política e de construção do conhecimento não hegemônico, polifônico e crítico.

O pano de fundo dos debates e espaços de construção foi extremamente desafiador, com idas e voltas, negociações e acordos mútuos entre todas as organizações, instituições, movimentos sociais e mulheres que estiveram envolvidas. É importante ressaltar que as metodologias feministas apresentadas no presente texto, nem sempre foram destituídas de conflitos, contradições e mal-entendidos. Eram muitos e diversos os sentimentos, as opiniões, os argumentos, que foram fundamentais para fortalecer a nossa construção coletiva, desencadeando em constantes momentos de aprendizados, desconstruções e em certas medidas de inseguranças, pois nem sempre é fácil deixar de seguir "as velhas receitas de bolos"!

Não reinventamos a roda, mas nos permitimos desestabilizar, criar o estranhamento desde dentro, entre nós mesmas, e assim, ampliar o debate, avançar na diversidade, criando espaços seguros de discussão que nos possibilitassem novos olhares e percepções, que certamente não se encerram 
com este Projeto e que hoje se desdobra com a Rede ATER, Feminismo e Agroecologia do Nordeste.

\section{Referências}

BUTTO, Andrea; HORA, Karla. Ater para mulheres: experiências recentes do governo federal. In: Assessoria Técnica com Mulheres: uma abordagem feminista e agroecológica. Cadernos Feministas de Economia \& Política. Recife: Casa da Mulher do Nordeste, n. 4, 2008. p. 131-160.

CALAÇA, Michela; WATANABE, Célia. Mulheres rurais e assistência técnica e extensão rural: uma trajetória de resistência e luta pela valorização e reconhecimento de suas reais demandas. In: JALIL, Laeticia Medeiros; ESMERALDO, Gema Galgani Silveira Leite; OLIVEIRA, Maria do Socorro de Lima (Orgs.) Rede Feminismo e Agroecologia do Nordeste. Recife: Rede Feminismo e Agroecologia do Nordeste, 2018. p. 129-145.

FONSECA, Maria Teresa L. da. A extensão rural no Brasil: um projeto educativo para o capital. Coleção educação popular. n.3. São Paulo: Loyola, 1985.

FREIRE, Paulo. Educação como prática da liberdade. 23a ed. Rio de Janeiro: Paz e Terra, 1999.

GORAYEB, Adryane; MEIRELES, Jeovah. Cartografia Social vem se consolidando como instrumento de defesa de direitos. Rede Mobilizadores, 10 fev.2014 Disponível em: http://www.mobilizadores.org.br/entrevistas/cartografia-social-vem-seconsolidando-com-instrumento-de-defesa-de-direitos/

HARAWAY, Donna. Saberes localizados: a questão da ciência para o feminismo e o privilégio da perspectiva parcial. Cadernos Pagu (5), Campinas-SP, Núcleo de Estudos de Gênero - Pagu/Unicamp, 1995, pp.7-41.

HOOKS, bell. El feminismo es para todo el mundo. Ed. Traficantes de Sueños, Madrid, 2017.

SANTOS, Ana Célia de Sousa; BOMFIM, Maria do Carmo Alves do. Pedagogia feminista na construção de uma "alternativa de Gênero". In: Anais... Fazendo Gênero 9 - Diásporas, Diversidades, Deslocamentos. Florianópolis, agosto, 2010.

SILIPRANDI, Emma Cademartori. Mulheres e Agroecologia: a construção de novos sujeitos políticos na agricultura familiar. 2009. 291f. Tese (Doutorado em Desenvolvimento Sustentável) - Centro de Desenvolvimento Sustentável, Universidade de Brasília, Brasília-DF, 2009.

SILVA, Carmen. Experiências em pedagogia feminista. Recife: SOS CORPO Instituto Feminista para a Democracia, 2010. 128p.

UFRPE. No tempo das mulheres: a experiência da cartografia feminista no contexto da assistência técnica rural. Recife, 2017a.

UFRPE. Autonomia e luta: experiência de Metodologias Feministas/ Rede ATER Agroecologica e Feminista do Nordeste. Recife, ActionAid, 2017b.

WEITZMAN, Rodica. Mulheres na assistência técnica e extensão rural. IN: BUTTO, Andrea; DANTAS, Isolda (Orgs.). Autonomia e cidadania: políticas de organização produtiva para as mulheres no meio rural. Brasília: Ministério do Desenvolvimento Agário, 2011. 87-111. 